\title{
Dyeing of Cotton, Bombyx Mori and Eri Silk Fabrics with the Natural Dye Extracted from Tamarind Seed
}

\author{
Supaluk Tepparin, Porntip Sae-be, Jantip Suesat, Sirisin Chumrum, and Wanissara Hongmeng
}

\begin{abstract}
This research studied the extraction of the natural dye from two different types of tamarind seed viz. sour-tamarind seed (TF) and sweet-tamarind seed (TO). The extracted dye solutions were prepared into a powder form and subsequently used for dyeing cotton and Bombyx Mori silk and Eri silk fabrics. From the experiment, the TF dye powder was easier soluble in water and could render a higher color strength than the TO dye powder. It was found for the tamarind-seed dyes that they could better exhausted on the silk fabrics than the cotton. Between the two silk fabrics, the dyes illustrated a higher degree of exhaustion on Bombyx Mori silk fabric than the Eri counterpart. The tamarind-seed dyes provide a reddish brown shade on the fabrics. This reddish brown shade could be altered when the dyed fabrics were put through the washing process. After washing, the shade of the dyed fabrics was more intense. The color fastness to washing of the dyed fabrics was in a good-excellent level. Even after experiencing 5-time washing, no significant shade change was observed on the dyed fabrics. The effect of mordants on the dyed fabrics was studied using three different mordants which were $\mathrm{ZnSo}_{4}, \mathrm{~K}_{2} \mathrm{Cr}_{2} \mathrm{O}_{7}$ and $\mathrm{FeSo}_{4}$. $\mathrm{The}_{\mathrm{ZnSo}}$ mordant was found to enhance the color fastness to washing to the dyed fabrics without causing any shade change, while using $\mathrm{K}_{2} \mathrm{Cr}_{2} \mathrm{O}_{7}$ as a mordant led to a shade alteration into a yellow brown but helped to stabilize the dye molecule, so such shade obtained was not sensitive to the washing condition. For the $\mathrm{FeSo}_{4}$ mordant, it also caused the shade change on the dyed fabrics to a dull grey shade but providing an excellent color fastness to washing.
\end{abstract}

Index Terms-Bombyx Mori silk, Eri silk, Cotton, Tamarind seeds, Natural dye, Mordant

\section{INTRODUCTION}

Tamarind (Tamarindus indica L.) is classified as an important economical plant being widely grown in Thailand. Tamarind is classified into 2 major kinds according to the providing taste of the tamarind fruits, namely sour tamarind and sweet tamarind. There are different types of sweet tamarind found in Thailand e.g. Srithong, Srichompoo,

Manuscript received April 25, 2012; revised May 30, 2012.

S. Tepparin is with the Department of Textile Science, Faculty of Agro-Industry, Kasetsart University, Bangkok, 10900, Thailand (e-mail: supaluk_ku@hotmail.com).

P. Sae-be is with the Department of Textile Science, Faculty of Agro-Industry, Kasetsart University, Bangkok, 10900, Thailand (corresponding author, phone: 66-2-5625065; fax: 66-2-9428663; e-mail: porntip.s@ku.ac.th ).

J. Suesat is with the Department of Textile Science, Faculty of Agro-Industry, Kasetsart University, Bangkok, 10900, Thailand (e-mail: Jantip.s@ku.ac.th ).

S. Chumrum is with the Department of Chemistry, Faculty of Science, Kasetsart University, Bangkok, 10900, Thailand (e-mail:sirisin.c@ku.ac.th).

W. Hongmeng is with the Department of Textile Science, Faculty of Agro-Industry, Kasetsart University, Bangkok, 10900, Thailand (e-mail: wanissarahingmeng@yahoo.com).
Khuntee and Prakaithong types while the sour tamarind found are Fukto and Srisaket 019 types [1]. Tamarind seed composes of about $70 \%$ kernel and $30 \%$ seed husk. The tamarind kernel comprises mainly tamarind gum which possesses viscous characteristics and being capable of forming gel, thus it can also be applied to use as a rheology modifier in food products. In addition, it can be used as an adhesive in paper industry and sizing agent in textile processing [2], [3].

In textile dyeing industry, most of the dyes employed are the synthetic azo dyes of which the azo bond cleavage brings about aromatic amines that may be harmful to human health and environment [4]. Nowadays, a great awareness on the impacts of toxic chemicals on the environment and human health has turned down the use of synthetic chemicals and in this circumstance, a higher demand is put towards the greener alternative substances [5]. For this reason, natural dyes are among the promising options for developing a greener textile dyeing process. However, the major drawback of the natural dyed-textiles is their poor color fastnesses to light and washing [6]. Incorporation of the mordants in natural dyeing can help to improve such inferior properties and at the same time, provides a wide variety of shades of natural dyes obtained on the same textiles substrates [7].

In our previous work [8], the extracted tamarind kernel which composes mainly of the hetero-polysaccharide compound, xyloglucan, was studied to use as a thickener for pigment printing on cotton fabric. The results found that the prepared tamarind gum had desired thickening properties for textile printing, providing color yield and rubbing fastness of the print comparable to those of the commercial synthetic thickener printing. Apart from the kernel, the reddish brown solution was also obtained from the tamarind seed extraction. Prabhu and Teli [2] studied on the extraction of tannin from the boiled tamarind seed solution and utilized it as a biomordant being used together with the metal mordant in natural dyeing of turmeric and pomegranate rind on cotton, silk and wool fabrics. It was reported that tannins could improve the color yield and color fastness properties on the mordant-dyed fabrics. Furthermore, it also rendered antibacterial properties against Staphylococcus and Escherichia coli. The current research concerns the preparation of a reddish brown dye powder from 2 different types of tamarind seed (Sweet tamarind and Sour tamarind) with the aim to facilitate the tamarind dye uses and to encourage the green substitution of the synthetic dyes to reduce environment problem. The dyeing properties of the tamarind-seed dye on cotton, Bombyx Mori silk and Eri silk fabrics were investigated. The $\%$ dye exhaustion, color strength and color fastness to washing of the dyed fabrics were examined. The effect of the mordants employed in the 
dyeing with the tamarind-seed dye was also studied.

\section{MATERIALS AND METHOD}

\section{A. Materials}

Tamarind seed were supplied from local market in Thailand. Sweet tamarind seeds (TO) and Sour tamarind seeds (TF) were used in this research, as shown in Fig 1. Woven cotton fabric with the weight of $114 \mathrm{~g} / \mathrm{m}^{2}$ which was already scoured and bleached was used. Bombyx Mori $(83$ $\left.\mathrm{g} / \mathrm{m}^{2}\right)$ and $\operatorname{Eri}\left(253 \mathrm{~g} / \mathrm{m}^{2}\right)$ silk woven fabrics were degummed and bleached before use. Sodium sulfate $\left(\mathrm{Na}_{2} \mathrm{SO}_{4}\right)$, zinc sulphate $\left(\mathrm{ZnSO}_{4} \cdot 7 \mathrm{H}_{2} \mathrm{O}\right)$, potassium dichromate $\left(\mathrm{K}_{2} \mathrm{Cr}_{2} \mathrm{O}_{7}\right)$ and ferrous sulphate $\left(\mathrm{FeSO}_{4} .7 \mathrm{H}_{2} \mathrm{O}\right)$ used were laboratory grade reagents.

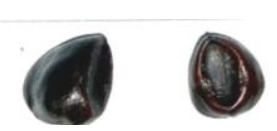

Sweet tamarind seeds (TO)

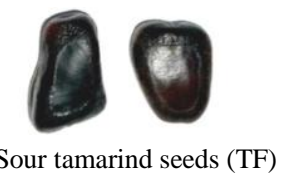

Sour tamarind seeds (TF)
Fig. 1. The shape of tamarind seeds

\section{B. Extraction of the Natural Dye from the Tamarind Seed}

Extraction of two different types of tamarind seed, sweet tamarind seed (TO) and sour tamarind seed (TF), was carried out by boiling the seeds in water until the seed husk got separated from the kernel. The reddish-brown extracted solution was left standing overnight to allow precipitation of the suspended insoluble portion. The solution part was filtered and subsequently taken to evaporate water out using a rotary evaporator. The obtained reddish brown dye was later oven-dried and ground into a fine powder with the particle size of approximately $150 \mu \mathrm{m}$.

\section{Dyeing of the Cotton and Silk Fabrics with the} Tamarind-Seed Dyes

The dye powder extracted from the tamarind seed husk was taken to study its dyeability on cotton, Bombyx Mori and Eri silk fabrics at the applied concentrations of 1, 3, 5, 7, 10 and $12 \%$ owf at a liquor ratio of $20: 1$. Sodium sulfate with the concentration of $5 \mathrm{~g} / \mathrm{l}$ was used a dyeing auxiliary. The dyeing process was performed at $85^{\circ} \mathrm{C}$ for 90 minutes. After that, the dyed fabrics was rinsed with water and dried at room temperature. The \% dye exhaustion was calculated from the absorbance of the dye solution before and after dyeing as depicted in equation (1).

$$
\% \text { Exhaustion }=\frac{\left(A_{0}-A_{1}\right)}{A_{0}} \times 100
$$

where $A_{\mathrm{o}}$ is the absorbance at $500 \mathrm{~nm}$ of the dye solution before dyeing.

$A_{1}$ is the absorbance at $500 \mathrm{~nm}$ of the dye solution after dyeing.

\section{Fixation of the Dye on the Fabrics with Mordants}

Investigation of the influence of the mordants on the shade and color fastness of each dyed fabrics was carried out by dyeing the fabrics with the tamarind-seed dye at $10 \%$ owf and $5 \mathrm{~g} / \mathrm{l}$ sodium sulfate salt was added. The fabrics were dyed at a liquor ratio of $20: 1$ at $85^{\circ} \mathrm{C}$ for 90 minutes. The after-treatment process of the dyed fabrics with the mordants, viz. $\mathrm{ZnSO}_{4} .7 \mathrm{H}_{2} \mathrm{O}, \mathrm{K}_{2} \mathrm{Cr}_{2} \mathrm{O}_{7}$ and $\mathrm{FeSO}_{4} .7 \mathrm{H}_{2} \mathrm{O}$, was performed at $3 \mathrm{~g} / \mathrm{l}$ mordant at $85^{\circ} \mathrm{C}$ for 30 minutes and the fabrics were then rinsed with water and dried at room temperature.

\section{E. Testing the properties of the dyed fabrics}

The shade and the color yield of the dyed fabrics were measured with Mcbeth ColorEye 7000 spectrophotometer. The color fastness to washing was determined according to ISO-105-C01 standard [9].

\section{RESUlTS AND DISCUSSION}

\section{A. Composition of the Tamarind Seeds}

By boiling the two different tamarind seeds in water, it was observed that the tamarind contained 2 major components which were the seed husk and the kernel. From our previous work, it was found that these two types of tamarind seed had a slightly different extent of the husk and the kernel components [8]. The dye powder which was to be used for dyeing the cotton and silk fabrics, was the soluble part accounting for about $55 \%$ by weight of both tamarind seed husks. The extracted dye achieved was a fine reddish brown powder. The dye powder derived from the sour tamarind seed was easier dissolved in water and attaining a clearer dye solution than that obtained from the sweet tamarind seed. The absorbance at the wavelength of $500 \mathrm{~nm}$ of the dye solutions at the same concentration was different. The light absorption of the dye solution from sweet tamarind seed was lower than that of the sour tamarind seed, indicating a less color strength and/or larger amount of water-soluble impurities present in the solution prepared from the TO dye. The condensed tannins which are a polyphenolic compound was reported to be presented in the solution of the tamarind-seed dye [2], [10].

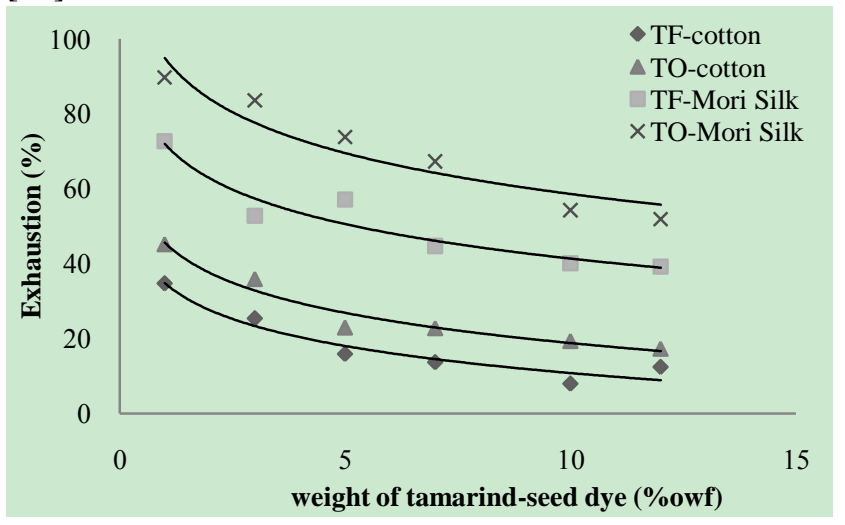

Fig. 2. \%Exhaustion of the tamarind-seed dye on cotton and silk fabric

\section{B. Dyeing of the Tamarind-seed Dyes on the Cotton and Silk Fabrics}

The degree of dye exhaustion is shown in Fig 2. The dye exhausted very well onto silk with the $\%$ exhaustion being higher than that on cotton. This can be explained by a better water absorption of silk and a more functional groups present in the structure of silk as compared with cotton. More positive charges on silk rendered a dye-binding capacity and higher dye-fiber bonding on silk fabrics. Both Bombyx Mori and Eri silk exhibited a higher color yield of the tamarind-seed dye than cotton (Fig 3). In addition, the higher exhaustion percentage was achieved for the case of TO dye 
both on the cotton and silk fabrics comparing with that of the TF dye. From Fig. 3, it was found that the fabrics dyed with the TF dye provided a higher visual color yield than the TO dyes, especially on silk. This indicates that the TF dye better dyed and bonded strongly to the fiber comparing with the TO dye. Furthermore, the TF dye was more soluble in water as compared with the TO dye, thus, the TF dye is more suited for dyeing on cotton and silk fabrics.

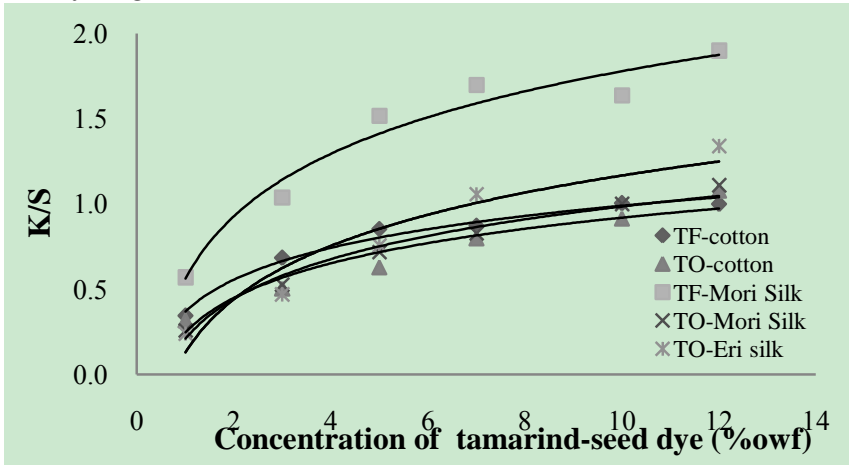

Fig. 3. The plots between the concentration of applied tamarind-seed dye and the $\mathrm{K} / \mathrm{S}$ values obtained on the cotton and silk fabrics.

The color yields attained on the cotton and silk fabrics dyed with the tamarind-seed dyes are shown in Fig 3. When the amount of applied dye increased, the color yield was increased, in particular on both Bombyx Mori and Eri silks, and the color properties of the dyed fabrics also changed with the amount of dye employed. The lightness ( $\left.\mathrm{L}^{*}\right)$ was lowered, while $a^{*}$ and $b^{*}$ was increased. The tamarind dye derived from different tamarind seed types rendered a different shade on the fabrics. The fabrics that had been through the dyeing process with the TF dye were darker (lower $\mathrm{L}^{*}$ ), redder, yellower and more intense in shade as compared with those dyed with TO dye. The dyeability of the tamarind-seed dye on the silk fabrics was superior to that on the cotton fabric. Between the two silk fabrics, the Eri silk was better dyeable than Bonbyx Mori silk because the loose, thick yarns with less twists provided a better water absorption and easier accessibility of the dye on Eri silk comparing with Bombyx Mori counterpart.

\section{Effect of Mordants}

Mordants or metal salts used as a fixing agent for dyeing affected the shade and the color fastness properties of the dyes. In this study, three different types of mordants were chosen for the investigation of their influence on the dyeing properties of tamarind-seed dyes. The effect of the mordants on the color properties of the cotton and silk fabrics dyed with the tamarind-seed dyes at $10 \%$ owf is shown in Table I.

It was observed from Table I that the fabrics dyed with the tamarind-seed dyes and aftertreated with different mordants exhibited higher color yields, especially in the case of ferrous sulfate, comparing with the fabrics without mordant. As the mordant is a metal salt compound, it can attract the dye molecules and form a complex structure with the dyes. As a result, the dyes are generally more strongly fixed on the fabrics. Therefore, the dyed fabrics which have been through mordanting process, normally have better fixation on the fabric.

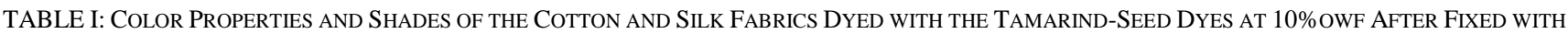
DIFFERENT MORDANTS

\begin{tabular}{|c|c|c|c|c|c|c|c|c|c|c|c|}
\hline \multirow{2}{*}{ Fabric } & \multirow{2}{*}{ Mordants } & \multicolumn{5}{|c|}{ TF-dye } & \multicolumn{5}{|c|}{ TO-dye } \\
\hline & & $\mathrm{L}^{*}$ & $a^{*}$ & $\mathrm{~b}^{*}$ & $\mathrm{~K} / \mathrm{S}$ & shade & $\mathrm{L}^{*}$ & $\mathrm{a}^{*}$ & $\mathrm{~b}^{*}$ & $\mathrm{~K} / \mathrm{S}$ & shade \\
\hline \multirow[t]{4}{*}{ Cotton } & $-\ldots$ & 68.33 & 16.48 & 10.25 & 0.91 & Bright reddish brown & 69.50 & 13.70 & 11.38 & 0.83 & Orange brown \\
\hline & $\mathrm{ZnSO}_{4}$ & 63.16 & 14.75 & 8.31 & 1.17 & Light reddish brown & 63.32 & 13.52 & 10.67 & 1.19 & Light reddish brown \\
\hline & $\mathrm{K}_{2} \mathrm{Cr}_{2} \mathrm{O}_{7}$ & 53.35 & 11.85 & 19.45 & 2.40 & Yellowish brown & 54.83 & 11.38 & 17.70 & 2.18 & Yellowish brown \\
\hline & $\mathrm{FeSO}_{4}$ & 42.07 & 3.12 & 3.08 & 3.47 & Grey & 45.28 & 2.10 & 2.07 & 2.66 & Light grey \\
\hline \multirow[t]{4}{*}{ Mori-silk } & $\ldots$ & 62.75 & 16.38 & 18.98 & 1.66 & Reddish brown & 66.53 & 13.02 & 16.87 & 1.17 & Light reddish brown \\
\hline & $\mathrm{ZnSO}_{4}$ & 62.75 & 14.45 & 17.38 & 1.55 & Reddish brown & 63.44 & 12.46 & 16.51 & 1.38 & reddish brown \\
\hline & $\mathrm{K}_{2} \mathrm{Cr}_{2} \mathrm{O}_{7}$ & 43.72 & 13.86 & 17.80 & 5.60 & Dark brown & 49.34 & 11.67 & 18.63 & 3.92 & Golden brown \\
\hline & $\mathrm{FeSO}_{4}$ & 34.68 & 0.724 & 2.76 & 5.58 & Dark grey & 40.02 & 0.56 & 4.41 & 4.16 & Medium-dark grey \\
\hline \multirow[t]{3}{*}{ Eri-silk } & - & 57.70 & 16.42 & 12.43 & 1.75 & Light reddish brown & 61.05 & 13.91 & 12.35 & 1.32 & Light reddish brown \\
\hline & $\mathrm{K}_{2} \mathrm{Cr}_{2} \mathrm{O}_{7}$ & 48.06 & 12.03 & 14.09 & 2.87 & Deep brown & 54.15 & 10.49 & 14.74 & 1.91 & Deep brown \\
\hline & $\mathrm{FeSO}_{4}$ & 37.41 & 2.65 & 7.71 & 4.73 & Dull grey & 40.92 & 2.60 & 9.91 & 3.81 & Dull grey \\
\hline
\end{tabular}

TABLE II: Staining ANd Shade Change From the WASH FASTNESS TESTING OF THE FABRICS Dyed with the TAMARIND-SEED Dyes

\begin{tabular}{|c|c|c|c|c|c|c|c|c|c|c|c|c|c|c|}
\hline & \multirow[b]{2}{*}{ Fabric } & \multirow[b]{2}{*}{ Mordant } & \multicolumn{7}{|c|}{ TF-dye } & \multicolumn{5}{|c|}{ TO-dye } \\
\hline & & & $\begin{array}{l}\text { Color } \\
\text { stain }\end{array}$ & $\begin{array}{l}\text { Color } \\
\text { change }\end{array}$ & $-\mathbf{D L}$ & $\begin{array}{c}\text { Shade } \\
-\mathbf{D a} \\
\mathrm{Da}^{*}\end{array}$ & $\begin{array}{c}\text { color } \\
b^{*}\end{array}$ & $\overline{\mathrm{K} / \mathrm{S}}$ & $\begin{array}{l}\text { Color } \\
\text { stain }\end{array}$ & $\begin{array}{l}\text { Color } \\
\text { change }\end{array}$ & $-\overline{\mathrm{DL}^{*}}$ & $\begin{array}{c}\text { Shade } \\
\mathrm{Da}^{*}\end{array}$ & $\frac{\text { color }}{\mathrm{Db}^{*}}$ & $\underset{\mathrm{K} / \mathrm{S}}{-}$ \\
\hline \multirow{4}{*}{ 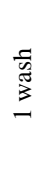 } & \multirow[t]{4}{*}{ Cotton } & & $5-4 / 5$ & $4 / 5$ & 0.36 & 0.13 & 3.23 & 1.67 & $5-4 / 5$ & $4 / 5$ & -10.90 & 2.79 & 2.06 & 1.68 \\
\hline & & $\mathrm{ZnSO}_{4}$ & 5 & $4 / 5$ & -7.67 & 1.72 & 4.97 & 2.02 & 5 & $4 / 5$ & -6.30 & 1.52 & 2.47 & 1.83 \\
\hline & & $\mathrm{K}_{2} \mathrm{Cr}_{2} \mathrm{O}_{7}$ & 5 & 5 & 0.15 & 0.44 & -0.67 & 2.34 & 5 & 5 & 0.37 & 0.18 & -0.80 & 2.05 \\
\hline & & $\mathrm{FeSO}_{4}$ & 5 & $3 / 4$ & -0.94 & 3.51 & 1.98 & 3.93 & 5 & 4 & -2.62 & 6.27 & 2.80 & 3.63 \\
\hline
\end{tabular}




\begin{tabular}{|c|c|c|c|c|c|c|c|c|c|c|c|c|c|c|}
\hline & \multirow[t]{4}{*}{ Mori-silk } & $\therefore$ & 5 & $3 / 4$ & -7.54 & 0.97 & -4.70 & 2.23 & $5-4 / 5$ & 4 & -7.38 & 1.35 & -1.98 & 1.77 \\
\hline & & $\mathrm{ZnSO}_{4}$ & 5 & $3 / 4$ & -8.18 & 1.48 & -3.85 & 2.26 & 5 & $3 / 4$ & -5.22 & 0.92 & -2.15 & 1.84 \\
\hline & & $\mathrm{K}_{2} \mathrm{Cr}_{2} \mathrm{O}_{7}$ & 5 & 5 & 0.31 & -0.32 & -0.67 & 5.38 & 5 & 5 & 0.60 & -0.51 & -0.76 & 3.67 \\
\hline & & $\mathrm{FeSO}_{4}$ & 5 & $3 / 4$ & -3.06 & 4.35 & 0.07 & 6.99 & 5 & $3 / 4$ & -2.40 & 5.45 & 1.29 & 5.12 \\
\hline & \multirow[t]{3}{*}{ Eri-silk } & - & $5-4 / 5$ & $4 / 5$ & 1.21 & -3.23 & -1.27 & 1.43 & $5-4 / 5$ & $4 / 5$ & 0.65 & -2.90 & -0.85 & 4.86 \\
\hline & & $\mathrm{K}_{2} \mathrm{Cr}_{2} \mathrm{O}_{7}$ & 5 & $4 / 5$ & 2.22 & -0.77 & -1.14 & 2.38 & 5 & $4 / 5$ & 0.07 & -0.45 & -1.07 & 1.83 \\
\hline & & $\mathrm{FeSO}_{4}$ & 5 & $3 / 4$ & 1.03 & 3.02 & 0.48 & 4.64 & 5 & $3 / 4$ & 3.98 & 3.37 & 1.51 & 3.14 \\
\hline \multirow{11}{*}{ 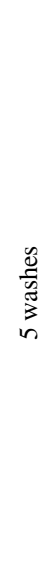 } & \multirow[t]{4}{*}{ Cotton } & - & 5 & $2 / 3$ & -10.74 & -2.04 & 5.65 & 1.85 & 5 & $2 / 3$ & -10.55 & -0.12 & 4.14 & 1.67 \\
\hline & & $\mathrm{ZnSO}_{4}$ & 5 & $3 / 4$ & -6.89 & -0.12 & 6.17 & 2.09 & 5 & $2 / 3$ & -7.51 & 0.01 & 3.14 & 1.89 \\
\hline & & $\mathrm{K}_{2} \mathrm{Cr}_{2} \mathrm{O}_{7}$ & 5 & $4 / 5$ & 1.58 & -0.19 & -0.84 & 2.86 & 5 & 4 & 1.61 & 0.11 & 0.07 & 2.58 \\
\hline & & $\mathrm{FeSO}_{4}$ & 5 & 3 & 1.07 & 4.63 & 4.00 & 3.62 & 5 & 3 & -1.92 & 5.63 & 4.25 & 3.52 \\
\hline & \multirow[t]{4}{*}{ Mori-silk } & - & 5 & $2-3$ & -12.51 & -0.15 & -3.27 & 3.29 & 5 & $2 / 3$ & -14.00 & 1.48 & 1.10 & 1.83 \\
\hline & & $\mathrm{ZnSO}_{4}$ & 5 & $2 / 3$ & -12.83 & 1.94 & -1.57 & 3.39 & 5 & $2 / 3$ & -10.38 & 1.38 & 0.30 & 2.85 \\
\hline & & $\mathrm{K}_{2} \mathrm{Cr}_{2} \mathrm{O}_{7}$ & 5 & $4 / 5$ & 2.08 & -0.61 & -0.06 & 4.87 & 5 & $4 / 5$ & 1.71 & -0.25 & 0.34 & 3.58 \\
\hline & & $\mathrm{FeSO}_{4}$ & 5 & 2 & -1.41 & 5.66 & 2.75 & 6.97 & 5 & 3 & -1.88 & 7.25 & 3.86 & 5.51 \\
\hline & \multirow[t]{3}{*}{ Eri-silk } & - & 5 & 4 & 0.20 & -5.29 & -1.07 & 1.47 & 5 & 4 & -2.34 & -3.22 & 0.87 & 1.41 \\
\hline & & $\mathrm{K}_{2} \mathrm{Cr}_{2} \mathrm{O}_{7}$ & 5 & $4 / 5$ & 0.45 & -0.29 & -0.63 & 2.69 & 5 & 4 & 5.95 & -2.08 & -2.47 & 1.18 \\
\hline & & $\mathrm{FeSO}_{4}$ & 5 & 3 & 2.46 & 4.03 & 2.32 & 4.39 & 5 & 3 & 0.47 & 5.35 & 3.79 & 4.23 \\
\hline
\end{tabular}

The shade obtained on the fabric changed with the mordant used. Samanta [11] reported that using ferrous sulfate as a mordant for natural dye fixation caused a shade change to be darker and mordanting with chromate brought about a change of shade to be brighter. The results on mordanting the dyed fabrics with $\mathrm{FeSO}_{4}$ showed a duller grey shade. The dyed fabrics treated with $\mathrm{K}_{2} \mathrm{Cr}_{2} \mathrm{O}_{7}$ appeared more yellow ( $b^{*}$ increased), the shade on the fabrics then turned to yellowish brown comparing with those without mordant. Virtually no change of shade was observed for the case of $\mathrm{ZnSo}_{4}$ and evenmore, its color fastness to washing was good, no staining being found on cotton fiber in the multifiber adjacent fabric (Table II).

\section{Wash fastness of the dyed fabrics}

The color fastness to washing of the dyed fabrics treated with different mordants is depicted in Table II. The results demonstrated that the fabrics dyed with the tamarind-seed dyes solely exhibited a good-very good fastness to washing. After 1 wash, a subtle staining was found on cotton and after 5 washes, there was no staining was observed. It elucidated that the tamarind-seed dye were attached firmly on the cotton and silk fibers, especially Bombyx Mori silk dyed with the TF dye. Furthermore, fixing the dyes with mordants helped to strengthen the dye-fiber bonding, therefore, the wash fastness properties obtained were excellent.

In addition, it was observed that the washing conditions used in the color fastness testing also caused shade change on the dyed fabrics both with/without mordant. More intense shade was developed after the fabric was brought to the fastness testing. This may be due to the instability of the dye molecules, resulting in a change in shade and color strength on the fabrics once the dyes were exposed to the conditions employed in the fastness testing. The dye molecules may be sensitive to alkalinity of the detergent solution at $40^{\circ} \mathrm{C}$. A change in the dye structure was then a reason for the increase in color depth on the fabrics. Mordanting the dye with $\mathrm{K}_{2} \mathrm{Cr}_{2} \mathrm{O}_{7}$ may enhance the structural stability to the dye molecule, therefore, the shade of the $\mathrm{K}_{2} \mathrm{Cr}_{2} \mathrm{O}_{7}$-fixed dye did not change after wash testing process. The $\mathrm{FeSO}_{4}$-treated fabrics which were deep grey, exhibited a brighter reddish brown shade after washing. This may be explained by the loss of $\mathrm{FeSO}_{4}$ from the fabric during washing, the less amount of the $\mathrm{FeSO}_{4}$ mordant on the fabric resulted in a less fixation of the dye and shade changed. From the results, it was found that the color fastness to washing of the tamarind-seed dyes was in a good-excellent level on the cotton and silk fabrics. Even passing through 5 washes, they could still retain their color strength, no color fading was observed. Even more, the shade of the dyes was brighter.

\section{CONCLUSION}

By simply boiling the tamarind seed in water, the water-soluble dye could be isolated and later used to dye the cotton and silk fabrics. The results generated in this research show a promising potential of the tamarind-seed dye to be applied practically in the craft industry where the uniqueness of the products is exploited. Preparation of the tamarind-seed dye into the powder form makes it more convenient for uses and the quality control on the shade obtained could be done more easily comparing with the solution dye. However, as the molecular structure of the tamarind-seed dye is rather unstable, the washing process may cause a shade variation more or less depending the washing conditions and the types of mordant employed in the dyeing. The study could be further investigated as to which parameters affect these properties of the dye and the way of improvement could be figured out and developed so as to encourage the utilization of this dye as a natural dye for the textile industry.

\section{ACKNOWLEDGMENT}

The authors are indebted to Kasetsart University Research and Development Institute for financial support of this research. A part of this research was funded by the Center of 
Advanced Studies for Agriculture and Food, KU Institute for Advanced Studies, Kasetsart University, Bangkok 10900, Thailand and finally, a great acknowledgement is given to the Center of Excellence in Silk, Kasetsart University.

\section{REFERENCES}

[1] W. Sittikijyothin and D. Cherdwongcharoensuk, "Free Radical Scavenging Activity of Seed Coat Extracts of Sweet and Sour Tamarinds," Burapha Science Journal, vol. 16, no. 1, pp. 47-55, 2011.

[2] K. H. Prabhu and M. D. Teli. (2011). Eco-Dyeing Using Tamarindus indica L. Seed Coat Tannin as a Natural Mordant for Textiles with Antibacterial Activity. [Online]. Journal of Saudi Chemical Society. Available: http://dx.doi.org/10.1016/j.jscs.2011.10.014

[3] The Wealth of India, "A Dictionary of Indian Raw Materials and Industrial Products," $5^{\text {th }}$ ed. CSIR, New Delhi, vol. 10, 2003, pp. $114-122$

[4] R. Ma. Melgoza, A. Cruz, and G. Buitrón. "Anaerobic/Aerobic Treatment of Colorants Present in Textile Effluents," Water Science and Technology. 5(2), 2004, 149-155.
[5] N. F. Ali and R. S. R. EL-Mohamedy, "Eco-Friendly and Protective Natural Dye from Red Prickly Pear (Opuntia lasiacantha Pfeiffer) Plant," Journal of Saudi Chemical Society vol. 15, no. 3, pp. 257-261, 2011.

[6] M. N. Micheal, F. M. Tera, and S. A. Aboelanwar. "Colour measurements and colourant estimation of natural red dyes on natural fabrics using different mordants," Colourage, vol. 1, pp. 31-42, 2003.

[7] R. Siva, "Review Article; Status of Natural Dyes and Dye-Yielding Plants in India," Current Science, vol. 92, no. 7, pp. 916-925, 2007.

[8] S. Tepparin, P. Sae-be, J. Suesat, and S. Chumrum, "Preparation of Tamarind-seed Thickener for pigment printing on cotton," Advance material research, pp. 233 -235, 1388-1399, 2011.

[9] International Organization for Standardization, Tests for colour fastness - Part C01: Colour fastness to washing, 1989.

[10] Y. Sydjaroen, Y. Haubner, R. Wurtele, G. Hull, W. E. Erben, G. Spiegelhalder, et al., "Isolation and Structure Elucidation of Phenolic Antioxidants from Tamarind (Tamarindus indica) Seeds and Pericap," Food and Chemical Technology, vol. 43, pp. 1673-1682, 2005.

[11] A. K. Samanta and A. Konar. "Dyeing of Textiles with Natural Dyes," in Natural Dyes, E. A. Kumbasar, Ed. InTech, 2011, pp. 29-57. 